\title{
论 文
}

\section{可见光驱动Methanosarcina barkeri-天然碳基 半导体产甲烷性能及机制}

\author{
张艺暳 ${ }^{1}$, 任国平 ${ }^{1}$, 胡安东 $^{1}$, 金曙光 $^{2}$, 叶捷 $^{1^{*}}$, 周顺桂 $^{1^{*}}$ \\ 1. 福建农林大学资源与环境学院, 福州 350002 ; \\ 2. 中国科学院生态环境研究中心, 北京 100085 \\ *E-mail: yejie@fafu.cn; sgzhou@soil.gd.cn \\ 收稿日期: 2020-10-11; 接受日期: 2020-12-09; 网络版发表日期: 2021-02-22 \\ 国家自然科学基金(批准号: 41925028, 41977281)资助项目
}

\begin{abstract}
摘要 利用半人工光合系统(非光合微生物-纳米半导体生物杂化体系)将二氧化碳转化为高热值的甲烷有助于缓 解全球温室效应和能源危机. 作为生物杂化体系的关键组分, 纳米半导体颗粒的结构及性质显著影响生物杂化体 系的性能. 本研究以油菜花粉为原料, 成功构建Methanosarcina barkeri-天然碳基半导体生物杂化体系 (M. barkeriNCS), 并将其应用于二氧化碳还原产甲烷过程. 结果表明, 所制备的天然碳基半导体具有可见光响应好、孔体积 大等优势. 在可见光 $\left(1.0 \pm 0.2 \mathrm{~mW} / \mathrm{cm}^{2}\right)$ 照射下, M. barkeri-NCS生物杂化体系具有良好的光电性能, 其甲烷产量最 高可达 $51 \pm 4.5 \mu \mathrm{mol} / \mathrm{g}$. 实时荧光定量多聚合酶链式反应结果进一步显示, M. barkeri膜结合氢酶和细胞色素相关基 因表达显著上调, 尤其是 $\mathrm{EchB}(2.47 \pm 0.25$ 倍 $)$ 和 $\mathrm{VhtC}(2.83 \pm 0.15$ 倍), 这表明这些基因在生物杂化体系光生电子传递捕获-利用过程中起着关键作用. 该研究结果有望为构建高效的半人工光合系统提供理论支撑.
\end{abstract}

关键词光催化, 产甲烷, 生物杂化体系, Methanosarcina barkeri, 天然碳基半导体

\section{1 引言}

随着工业化的快速发展，全球化石燃料的消耗量 日益增加，这不仅加剧了能源枯竭，也导致了二氧化 碳 $\left(\mathrm{CO}_{2}\right)$ 等温室气体的排放量急剧上升, 进而对人们赖 以生存的环境造成严重威胁. 因此, 将 $\mathrm{CO}_{2}$ 还原成高附 加值化学品对缓解温室效应和能源危机至关重要 ${ }^{[1,2]}$. 作为 $\mathrm{CO}_{2}$ 资源化的重要产物之一，甲烷 $\left(\mathrm{CH}_{4}\right)$ 是地球上 重要的生物质能源, 其热值高达 $890 \mathrm{~kJ} / \mathrm{mol}$. 因此将
$\mathrm{CO}_{2}$ 还原为 $\mathrm{CH}_{4}$ 不仅能够减缓温室效应, 而且可为化石 燃料替代品的开发提供潜在途径 ${ }^{[3]}$.

近年来, 光催化还原 $\mathrm{CO}_{2}$ 产 $\mathrm{CH}_{4}$ 作为新兴的研究方 向得到了科研人员的普遍关注 ${ }^{[4-6]}$. 这种人工光合技术 主要是利用丰富的太阳能激发半导体光催化材料产生 光生电子, 从而实现还原 $\mathrm{CO}_{2}$ 产 $\mathrm{CH}_{4}$. 该过程具有构成 简单、可设计性强、光合转化效率高于自然光合系统 等优势 ${ }^{[7]}$. 但这种单一的人工光合技术也存在还原产 物 $\left(\mathrm{CH}_{4} / \mathrm{H}_{2}\right)$ 选择性差等缺陷. 虽然有研究者通过使用

引用格式: 张艺韫, 任国平, 胡安东, 等. 可见光驱动Methanosarcina barkeri-天然碳基半导体产甲烷性能及机制. 中国科学: 技术科学, 2021, 51: 601-612 Zhang Y Y, Ren G P, Hu A D, et al. Visible light-driven Methanosarcina barkeri-natural carbon-based semiconductor for methane production (in Chinese). Sci Sin Tech, 2021, 51: 601-612, doi: 10.1360/SST-2020-0414 
生物酶催化剂来解决这一难题 ${ }^{[8]}$, 然而酶分离纯化的 复杂性 ${ }^{[9]}$ 、酶自身的不稳定性 ${ }^{[10]}$ 及氧的不耐受性 ${ }^{[11]}$ 限 制了该方法的推广应用. 与酶相比, 产甲烷菌等全细胞 微生物具有可自我修复/复制等特性, 且在复杂环境条 件下能量损失更小, 因此具有更广阔的应用前景. 最新 研究表明, 基于产甲烷菌高选择性生物催化能力与半 导体优越的光捕获特性所构建的半人工光合系统(生 物杂化体系)可以有效实现 $\mathrm{CO}_{2}$ 还原产 $\mathrm{CH}_{4}{ }^{[12]}$. 但目前 使用的半导体主要以硫化镉 $(\mathrm{CdS})$ 等金属化合物为 主 $^{[12,13]}$, 由此构建的生物杂化体系容易因为光腐蚀引 起重金属的释放，进而造成环境污染 ${ }^{[14]}$; 加之其带隙 较宽, 通常需要利用紫光等较强的光源激发, 不仅容 易对菌体造成光损伤 ${ }^{[15]}$ ，也不利于实际推广利用. 因 此开发新型的生物兼容性强的非金属半导体光催化材 料尤为重要.

碳基非金属半导体由于环境友好等特点而备受关 注 ${ }^{[16,17]}$. 相比于碳化氮 $(\mathrm{CN}) 、 \mathrm{~g}-\mathrm{C}_{3} \mathrm{~N}_{4}$ 等碳基材料, 利用 天然材料制备碳基半导体引起科研人员的极大兴 趣 ${ }^{[18]}$. 与传统化学合成相比, 这种制备方法具有材料 来源丰富、制备过程经济环保等优点，而且所制备的 碳基半导体存在均匀的多孔碳骨架结构，可应用于不 同的领域 ${ }^{[19,20]}$. Xiao 等人 ${ }^{[21]}$ 的研究结果显示，以花粉 为原料制备的天然碳基催化剂具有孔体积及比表面积 大等特性, 可提供丰富的气体吸附/活化位点. 此外, 该 材料所具有的分层空心结构不仅能够有效促进电子空穴对的分离, 而且能够通过内部光散射和反射提高 可见光的响应 ${ }^{[22]}$. 然而, 目前国内外对天然碳基半导 体的研究还主要集中于无机催化体系, 将其与微生物 相结合的探索仍处于初步阶段，已有的研究结果也主 要是证实天然碳基半导体的强氧化性能够有效实现杀 菌等功能 ${ }^{[18,23]}$. 对于天然碳基半导体能否与非光合产 甲烷菌形成高效的半人工光合系统尚不明确，特别是 该系统在可见光条件下能否驱动 $\mathrm{CO}_{2}$ 还原产 $\mathrm{CH}_{4}$ 过程 及相关机制也缺乏深入研究.

因此，本研究利用油菜花粉制备天然碳基半导体 (NCS), 选取Methanosarcina barkeri (M. barkeri)为模 式产甲烷菌株, 构建 $M$. barkeri-NCS生物杂化体系. 通 过对构建的生物杂化体系进行表征，探究其在可见光 条件下还原 $\mathrm{CO}_{2}$ 产 $\mathrm{CH}_{4}$ 潜能, 并对可能的电子传递机制 进行解析. 研究结果有望为构建高效的 $\mathrm{CO}_{2}$ 还原产 $\mathrm{CH}_{4}$ 生物杂化体系提供理论依据.

\section{2 材料与方法}

\section{1 天然碳基半导体的制备及 M. barkeri的培养}

根据Xiao等人 ${ }^{[21]}$ 的方法，将 $10 \mathrm{~g}$ 油菜花粉浸泡在 $100 \mathrm{~mL}$ 无水乙醇中，超声 $2 \mathrm{~h}$ 后过滤，并用去离子水清 洗数次. 然后将处理后的样品加入 $100 \mathrm{~mL}$ 乙醇和甲醛 $(v / v, 1: 1)$ 混合溶液中, 搅拌 $1 \mathrm{~h}$ 后过滤, 并用去离子水清 洗数次. 最后用 $\mathrm{H}_{2} \mathrm{SO}_{4}$ 溶液 $(12 \mathrm{~mol} / \mathrm{L}, 100 \mathrm{~mL})$ 对所得 到的样品进一步处理, 在 $80^{\circ} \mathrm{C}$ 水浴中搅拌 $4 \mathrm{~h}$ 后, 将产 物用去离子水冲洗至pH 7.0, 并在真空中干燥 $24 \mathrm{~h}$ 后 备用。

M. barkeri MS(DSM800)购买自德国DSMZ公司. 将获得的 $M$. barkeri接入以乙酸钠为碳源的DSM $311 \mathrm{~b}$ 培养基中，置于 $37^{\circ} \mathrm{C}$ 恒温培养箱中培养，收集对数期 的菌液, $4^{\circ} \mathrm{C}$ 保存作为原始菌液 ${ }^{[12]}$.

\subsection{M. barkeri-NCS生物杂化体系的构建及还原 $\mathrm{CO}_{2}$ 产 $\mathrm{CH}_{4}$ 实验}

在 $37^{\circ} \mathrm{C}$ 下，在 $10 \mathrm{~mL}$ DSM $311 \mathrm{~b}$ 培养基中接种 $0.5 \mathrm{~mL}$ M. barkeri原始菌液. 当 $M$. barkeri培养至生长 对数期 $\left(A_{600} \sim 0.2\right)$ 时, 加入 $2 \mathrm{mg} \mathrm{NCS}$ 构建 $M$. barkeri$\mathrm{NCS}$ 生物杂化体系. 经过 2 天的培养箱避光培养, 将生 物杂化体系在 $4^{\circ} \mathrm{C}, 7500 \mathrm{r} / \mathrm{min}$ 条件下离心 $6 \mathrm{~min}$, 用生 理盐水洗涤3次. 最终用 $1 \mathrm{~mL}$ 生理盐水重悬浮, 然后将 其立即加入到 $10 \mathrm{~mL}$ 以 $\mathrm{NaHCO}_{3}$ 为碳源的无机培养基 中, 并加入 $0.3 \mathrm{wt} \%$ 的半胱氨酸 $(\mathrm{Cys})$ 作为牺牲试剂 ${ }^{[24]}$. 此外, M. barkeri-CdS及 $M$. barkeri- $\mathrm{Ni}_{(0.75 \%)}: \mathrm{CdS}$ 生物杂 化体系是目前已报道的能够有效驱动 $\mathrm{CO}_{2}$ 还原产 $\mathrm{CH}_{4}$ 的生物杂化体系，但这两种体系的产 $\mathrm{CH}_{4}$ 过程均是在 紫光激发下进行的，对于其在可见光全波段下的产 $\mathrm{CH}_{4}$ 性能尚不明确. 因此，本文同时选取M. barkeri$\mathrm{CdS}$ 及 $M$. barkeri- $\mathrm{Ni}_{(0.75 \%)}$ : $\mathrm{CdS}$ 生物杂化体系为研究对 象，探究其在可见光全波段下的产 $\mathrm{CH}_{4}$ 性能，并与 M. barkeri-NCS生物杂化体系进行比较. 在构建 M. barkeri-CdS及 $M$. barkeri $-\mathrm{Ni}_{(0.75 \%)}: \mathrm{CdS}$ 生物杂化体 系过程中, 我们将 M. barkeri-NCS生物杂化体系中的NCS 替换为等量的 $\mathrm{CdS}$ 及 $\mathrm{Ni}_{(0.75 \%)}: \mathrm{CdS}$. 在比较不同半导体 所构建的生物杂化体系的产 $\mathrm{CH}_{4}$ 性能的实验中，原体 系中的 NCS 需要替换为等量的 $\mathrm{CdS}$ 及 $\mathrm{Ni}_{(0.75 \%)}: \mathrm{CdS}$, 构 建 $M$. barkeri-CdS及 $M$. barkeri- $\mathrm{Ni}_{(0.75 \%)}$ : $\mathrm{CdS}$ 生物杂化 体系 ${ }^{[12,13]}$. 所有的培养和取样操作都在厌氧手套箱中 
进行.

以发光二极管(LED)灯 (380 780 nm)为模拟可见 光光源, 在 $1.0 \pm 0.2 \mathrm{~mW} / \mathrm{cm}^{2}$ 下, 进行 $M$. barkeri-NCS生 物杂化体系还原 $\mathrm{CO}_{2}$ 产 $\mathrm{CH}_{4}$ 性能研究. 设置对照试验评 估M. barkeri, NCS和光照三个要素在还原 $\mathrm{CO}_{2}$ 产 $\mathrm{CH}_{4}$ 过程中的作用，并探究不同天然碳基半导体投加量 $(0.05,0.1,0.2,0.4,0.8 \mathrm{mg} / \mathrm{mL})$ 、不同半导体 $(\mathrm{CdS}$, $\mathrm{Ni}_{(0.75 \%)}: \mathrm{CdS}$ 和NCS)、不同光强 $(0.4,0.8,1.0,1.2$, $\left.1.6 \mathrm{~mW} / \mathrm{cm}^{2}\right)$ 及光暗循环 $(12 \mathrm{~h} / 12 \mathrm{~h})$ 下生物杂化体系产 $\mathrm{CH}_{4}$ 性能. 采用日本岛津 $\mathrm{GC} 2014$ 气相色谱仪测定 $\mathrm{CH}_{4}$ 的浓度，并计算M. barkeri-NCS生物杂化体系的平

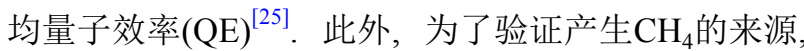
设置对照试验, 将洗菌后培养基中的 $\mathrm{NaH}^{12} \mathrm{CO}_{3}$ 用 $\mathrm{NaH}^{13} \mathrm{CO}_{3}$ 代替，然后用Agilent $7890-5975 \mathrm{c}$ 气相色谱质谱仪在所选离子监测(SIM) $(m / z=17,45)$ 模式测定顶 空气体质谱.

\section{3 表征方法}

将NCS固定在硅片上，并使用日本日立SU8020进 行场发射扫描电子显微镜(FESEM)成像. 此外, 将收集 的M. barkeri-NCS生物杂化体系样品用 $2.5 \%$ 戊二醛固 定 $12 \mathrm{~h}$, 用不同浓度乙醇 $(30 \%, 50 \%, 70 \%, 80 \%, 90 \%$ 和 $95 \%$ )梯度洗脱, 然后保存至 $100 \%$ 的乙醇中 ${ }^{[26]}$. 将悬浊 液滴在碳膜上，在室温 $\left(25^{\circ} \mathrm{C}\right)$ 下干燥. 使用美国Tecnai G2 F20 S-TWIN进行透射电子显微镜(TEM)成像, 并通 过附加在TEM上的X-MaxN能量色散X射线检测器 (EDS)分析生物杂化体系表面的元素组成. X射线衍射 光谱(XRD)采用日本岛津XRD-6000型X射线衍射仪进 行测定，以 $\mathrm{Cu}$ 靶 $\mathrm{K} \alpha$ 线作为辐射源，工作电压为 $40 \mathrm{kV}$, 工作电流为 $30 \mathrm{~mA}$, 扫描速度为 $1 \% \mathrm{~min}$, 扫描范围为 $5^{\circ}$ $\sim 80^{\circ[27]}$. 使用美国赛默飞的IS 50 FTIR测定傅立叶变换 红外(FTIR)光谱 ${ }^{[28]}$. 使用Thermo ESCALA 250 XPS光 谱仪系统进行能谱分析，以 $\mathrm{Al}$ 靶 $\mathrm{K} \alpha$ 线作为辐射源，测 试能量为 $30 \mathrm{eV}$, 并通过XPS PEAK41软件拟合峰 ${ }^{[29]}$.

利用日本岛津UV2600紫外可见光谱仪测定样品 漫反射光谱. 利用上海辰华 $\mathrm{CHI} 760 \mathrm{E}$ 电化学工作站分别 在1.0和 $1.5 \mathrm{kHz}$ 下进行莫特-肖特基测试. 利用上海辰华 CHI 660E电化学工作站进行光电流 $(I-t)$ 和电化学阻抗谱 (EIS)测定，其中氧化铟锡(ITO)导电玻片 $(1 \mathrm{~cm} \times 1 \mathrm{~cm})$ 为工作电极, 铂电极和饱和甘录电极分别为对电极和 参比电极 ${ }^{[12]}$.
利用Sigma-Aldrich MAK037定量试剂盒测定还 原/氧化型辅酶 $\mathrm{I}(\mathrm{NADH} / \mathrm{NAD})$ 比值, 以评估 $\mathrm{CO}_{2}$ 还原产 $\mathrm{CH}_{4}$ 过程中 M. barkeri胞内氧化还原当量变化. 利用 Sangon Biotech BSP02一步法细菌活性蛋白提取试剂 盒提取M. barkeri活性蛋白, 并使用Thermo Scientific Pierce BCA蛋白质分析试剂盒测定总蛋白浓度. 利用 Qiagen RNeasy Mini试剂盒对不同条件下的生物杂化 体系样品进行RNA的提取和纯化. 纯化的RNA通过 KR118 FastKing gDNA Dispelling RT SuperMix试剂 盒反转录为 $\mathrm{cDNA}$ 模板. 针对 $E c h, V h t, H d r, m c r A$ 和内 参基因 rpoAl 设计了相应引物 ${ }^{[12]}$, 所有引物均经聚合 酶链式反应 $(\mathrm{PCR})$ 验证. 实时荧光定量 $\mathrm{PCR}(\mathrm{qPCR})$ 通 过Roche LightCycler 480系统进行. 反应体系总体积 为 $20 \mu \mathrm{L}$, 包括 $10 \mu \mathrm{L}$ iTaq Universal SYBR Green Supermix、 $1 \mathrm{mmol} / \mathrm{L}$ 基因特异性引物、 $3 \mu \mathrm{L}$ 无菌水和 $50 \mathrm{ng}$ cDNA. 以 $60^{\circ} \mathrm{C}$ 为退火温度, 进行 40 个周期.

所有实验都进行了三次重复. 采用 $t$ 检验, $P<0.05$ 为存在显著性差异, 有统计学意义.

\section{3 结果与分析}

\section{1 天然碳基半导体表征}

FESEM结果(图1(a))显示, 以油菜花粉为原料制备 的NCS颗粒呈现出均匀的椭圆形形貌，其长和宽分别 约为 28 和 $21 \mu \mathrm{m}$, 且具有中空的壳状结构, 表明NCS成 功保留了油菜花粉的原始形态和结构. 高倍FESEM图 像(图1(b))和TEM图像(图1(c))进一步证明, NCS颗粒 表面由多孔的中空网络结构组成, 其中均匀分布着大 量的孔径，这为天然碳基半导体收集光能和吸附、传 递 $\mathrm{CO}_{2}$ 提供了有利条件 ${ }^{[30]}$. 此外, XRD图谱(图1(d))显 示, 在 $22^{\circ}$ 左右存在较宽的衍射峰，这表明形成了近似 非晶态材料 ${ }^{[31]}$. XPS谱图(图1(e), (f))显示, NCS 主要存 在 C, O, N和S四种元素, 元素占比分别为 $74.93 \%$, $20.02 \%, 2.94 \%$ 和 $2.11 \%$. 这其中 C $1 \mathrm{~s}$ 主要在结合能为 $284.8 ， 286.3$ 和 $288.6 \mathrm{eV}$ 处有三个特征峰，这表明 NCS 中存在 $\mathrm{C}-\mathrm{C}, \mathrm{C}-\mathrm{NR}_{2}$ 和 $\mathrm{O}-\mathrm{C}=\mathrm{O} \mathrm{O}^{\text {键 }}{ }^{[32]} ; \mathrm{O}$ 1s则主要在结 合能为 $532.0,533.5$ 和 $536.0 \mathrm{eV}$ 处有四个特征峰, 这表 明 NCS中存在 $\mathrm{C}=\mathrm{O}, \mathrm{C}-\mathrm{OH}$ 和 $\mathrm{O}-\mathrm{C}=\mathrm{O}^{[33,34]} ; \mathrm{N}$ 1s 在结合 能为 399.8 和 $401.1 \mathrm{eV}$ 处有特征峰, 这表明 NCS中存在

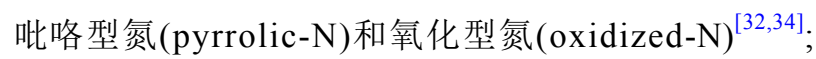
S $2 p$ 在结合能为 168.9 和 $170.1 \mathrm{eV}$ 处有特征峰, 这表明 

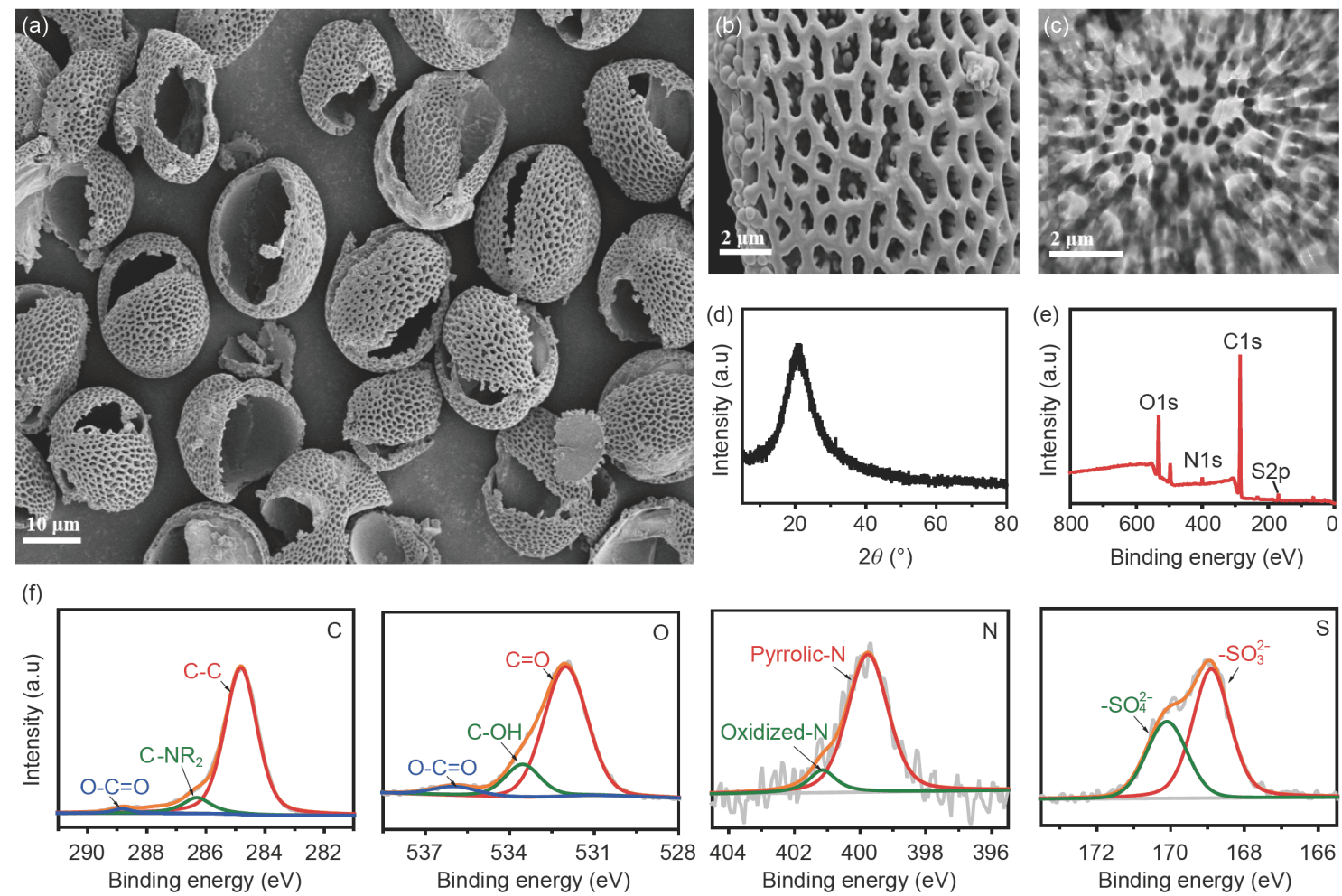

图 1 (网络版彩图)合成的NCS颗粒表征. (a), (b) FESEM图像; (c) TEM图像; (d) XRD图谱; (e) XPS全光谱; (f) C, O, N和S各元 素的XPS光谱

Figure 1 (Color online) Characterizations of the NCS. (a), (b) FESEM image; (c) TEM image; (d) XRD pattern; (e) XPS spectra of survey; (f) XPS spectra of $\mathrm{C}, \mathrm{O}, \mathrm{N}$ and $\mathrm{S}$.

$\mathrm{NCS}$ 中存在 $\mathrm{SO}_{3}{ }^{2-}$ 和 $\mathrm{SO}_{4}{ }^{2-}{ }^{[35]}$, 这可能是由于制备 $\mathrm{NCS}$ 时使用了 $\mathrm{H}_{2} \mathrm{SO}_{4}{ }^{[36]}$. 由这些结果可知, 所制备的 NCS半 导体是以 $\mathrm{C}$ 为主要元素, 并掺杂 $\mathrm{N}$ 和 $\mathrm{S}$ 等元素的多孔碳 基材料.

\section{2 构建 $M$. barkeri-NCS生物杂化体系}

由图2(a)可知，多孔的NCS与 $M$. barkeri具有不同 的形貌结构. 八叠球状的M. barkeri与 $\mathrm{NCS}$ 有良好的接 触，且部分M. barkeri嵌入到NCS结构中，从而有效形 成生物杂化体系. TEM高角环形暗场像(图2(b))及元素 分布(图2(d))结果显示, M. barkeri-NCS生物杂化体系 主要由 $\mathrm{C}, \mathrm{O}, \mathrm{N}$ 和 $\mathrm{S}$ 四种元素组成且分布较为均匀. 此 外, 通过FTIR光谱(图2(c))显示, M. barkeri-NCS生物杂 化体系有多处明显的特征峰, 这些特征峰意味着生物 杂化体系主要由 $\mathrm{C}=\mathrm{O}\left(1658 \mathrm{~cm}^{-1}\right), \mathrm{C}-\mathrm{H}(1206$ 和 $\left.2927 \mathrm{~cm}^{-1}\right), \mathrm{O}-\mathrm{H}\left(3292 \mathrm{~cm}^{-1}\right)$ 以及 $\mathrm{CO}_{3}{ }^{2-}\left(1542 \mathrm{~cm}^{-1}\right)$ 等 官能团组成 ${ }^{[34,37,38]}$, 进而表明生物杂化体系主要由C,
$\mathrm{O}$ 和H元素组成 ${ }^{[39]}$. 此外, 结合NSC的XPS结果可知, 生物杂化体系表面存在着丰富的羟基(-OH)基团. 已 有研究表明, - $\mathrm{OH}$ 基团能够有效促进电荷转移，从而 抑制光生电子与空穴的复合 ${ }^{[40]}$, 进而使生物杂化体系 在还原 $\mathrm{CO}_{2}$ 产 $\mathrm{CH}_{4}$ 过程中更具优势. 此外, 其他官能团 在光照前后没有发生显著性变化, 且峰位置也相对比 较稳定, 由此证明 $M$. barkeri-NCS生物杂化体系具有 较高的结构稳定性.

\subsection{M. barkeri-NCS生物杂化体系光电性能}

为了研究 M. barkeri-NCS生物杂化体系的光电性 能, 我们首先对NCS的能带结构进行了测定. 由紫外可见光固体漫反射光谱(图3(a))可知, NCS 催化剂的带 隙宽度 $\left(E_{\mathrm{g}}\right)$ 约为 $2.06 \mathrm{eV}\left(\lambda_{\text {吸收 }}=599 \mathrm{~nm}\right)$, 小于 $\mathrm{CdS}$ 等硫族 半导体的带隙宽度 ${ }^{[41]}$, 这意味着NCS 具有更强的可见 光吸收能力. 莫特-肖特基扫描结果显示, 在不同频率 $(1.0$ 和 $1.5 \mathrm{kHz})$ 下的曲线斜率均为正值(图3(b)), 表明所 

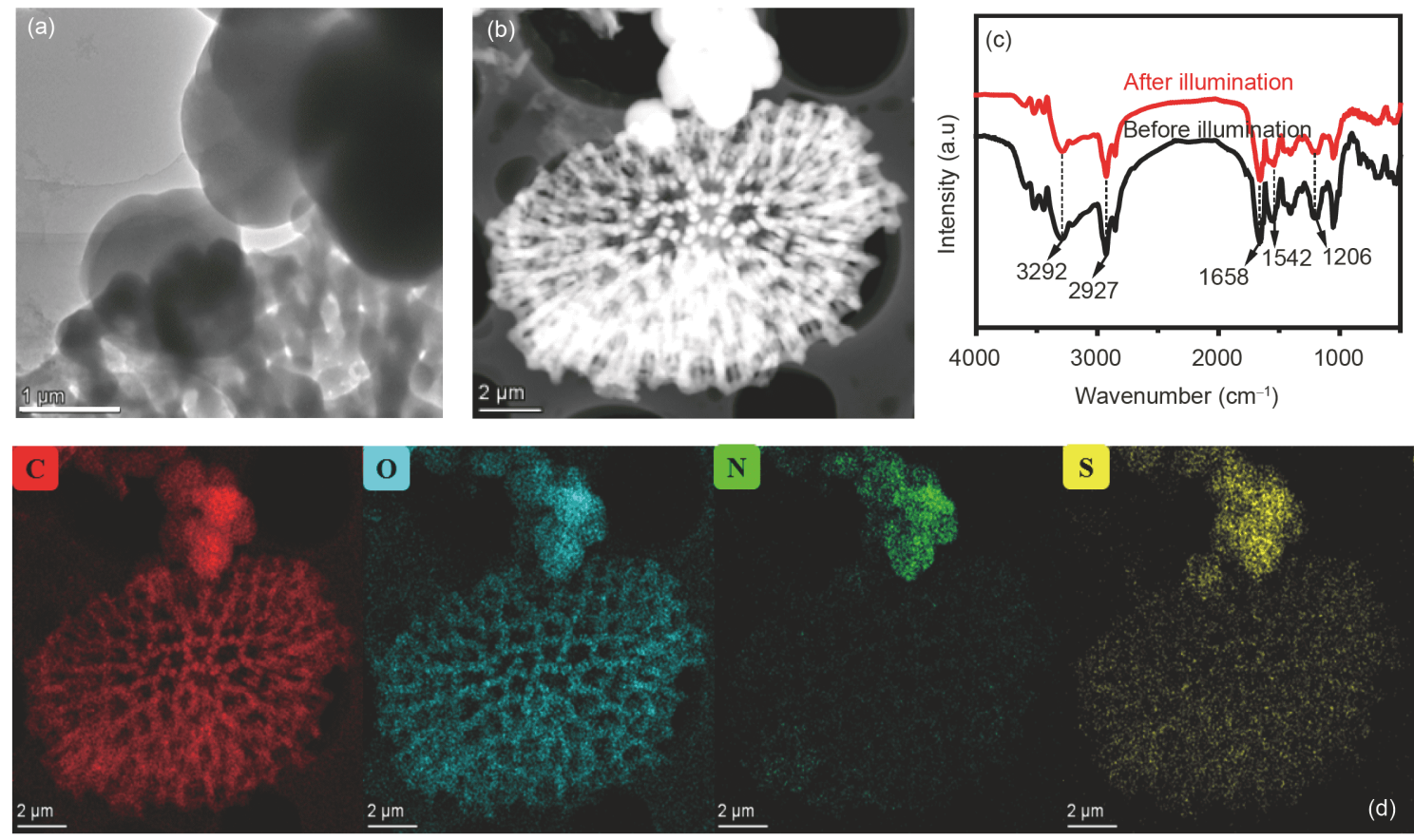

图 2 (网络版彩图) M. barkeri-NCS生物杂化体系的形貌表征. (a) TEM图像; (b) TEM高角环形暗场像; (c) FTIR谱图; (d) C, O, $\mathrm{N}$ 和S 各元素分布的EDS图像

Figure 2 (Color online) Characterizations of the M. barkeri-NCS biohybrids. (a) TEM image; (b) TEM high-angle annular dark-field image; (c) FTIR spectra; (d) elements mapping images of $\mathrm{C}, \mathrm{O}, \mathrm{N}$ and $\mathrm{S}$ by EDS.

制备的NCS催化剂是 $\mathrm{n}$ 型特征半导体，这有利于 $\mathrm{CO}_{2}$ 的 还原. 同时, 由其外推距可知, 所制备的NCS催化剂的 最低未占据分子轨道( $(\mathrm{LUMO})$ 为 $-1.05 \mathrm{~V}$ vs. $\mathrm{Ag} / \mathrm{AgCl}$ $(-0.85 \mathrm{~V}$ vs. 标准氢电极(NHE)). 由此可知NCS催化剂 的导带电位大约位于 $-0.85 \mathrm{eV}$, 满足 $\mathrm{CO}_{2}$ 还原为 $\mathrm{CH}_{4}$ 的 氧化还原电位要求 ${ }^{[22,43]}$. I- $t$ 曲线(图3(c))进一步表征生 物杂化体系的光电性能. 结果显示, 生物杂化体系在 光照后的光电流立即增加, 可以产生 $0.05 \sim 0.10 \mu \mathrm{A}$ 的 光电流，在停止光照后立即下降. 相比之下，M. barkeri-NCS生物杂化体系的光电流高于单独NCS. 这表 明 $M$. barkeri可以有效接收NCS产生的光电子, 从而促 进光生电子转移 ${ }^{[44]}$. 阻抗拟合结果(图3(d)) 也进一步证 实, 光照条件下 $M$. barkeri-NCS生物杂化体系具有更小 的界面电荷转移电阻, 这与 $I-t$ 曲线结果一致.

\subsection{M. barkeri-NCS生物杂化体系产 $\mathrm{CH}_{4}$ 性能}

我们首先探究不同光强、碳基半导体投加量及牺 牲试剂Cys浓度对 $M$. barkeri-NCS生物杂化体系产 $\mathrm{CH}_{4}$ 性能的影响. 实验结果显示, 当光强为 $1.0 \pm$
$0.2 \mathrm{~mW} / \mathrm{cm}^{2}$ 、天然碳基半导体投加量为 $2 \mathrm{mg} / \mathrm{mL}$ 、牺 牲试剂浓度为 $0.3 \mathrm{wt} \%$ 时, 生物杂化体系产 $\mathrm{CH}_{4}$ 性能达 到最佳. 因此, 在接下来的研究中我们以此参数开展 进一步的研究. 如图 4(a)所示, 随着光照的进行, M. barkeri-天然碳基半导体生物杂化体系产 $\mathrm{CH}_{4}$ 量逐 渐增加. 在光照三天后, M. barkeri-NCS生物杂化体系 产 $\mathrm{CH}_{4}$ 量可达 $51 \pm 4.5 \mu \mathrm{mol} / \mathrm{g}$, 该结果显著优于 $M$. barkeri-CdS及 $M$. barkeri- $\mathrm{Ni}_{(0.75 \%)}$ : $\mathrm{CdS}$ 生物杂化体系(图4 (b)). 由于 $\mathrm{Ni}_{(0.75 \%)}: \mathrm{CdS}$ 及 $\mathrm{CdS}$ 禁带宽度较大 $(2.66 \sim 2.68 \mathrm{eV})$, 需要更强的光源激发. 而本研究使用 的光源中紫光含量相对较低, 限制了M. barkeri-CdS及 M. barkeri- $\mathrm{Ni}_{(0.75 \%)}: \mathrm{CdS}$ 生物杂化体系光生电子的产生 及捕获，从而导致二者产 $\mathrm{CH}_{4}$ 量没有显著差异，均在 $10.6 \mu \mathrm{mol} / \mathrm{g}$ 左右. 为了进一步研究M. barkeri-NCS生 物杂化体系光催化产 $\mathrm{CH}_{4}$ 的关键驱动因子, 我们设计 了相关对照实验. 如图4(a)所示, 单纯 $M$. barkeri在黑 暗条件下产生了微量 $\mathrm{CH}_{4}($ 约 $3.9 \mu \mathrm{mol} / \mathrm{g})$, 这可能是由 M. barkeri在培养过程中残留的中间代谢产物引起 的 ${ }^{[12]}$. 但是在光照条件下, 单纯M. barkeri的 $\mathrm{CH}_{4}$ 生成 

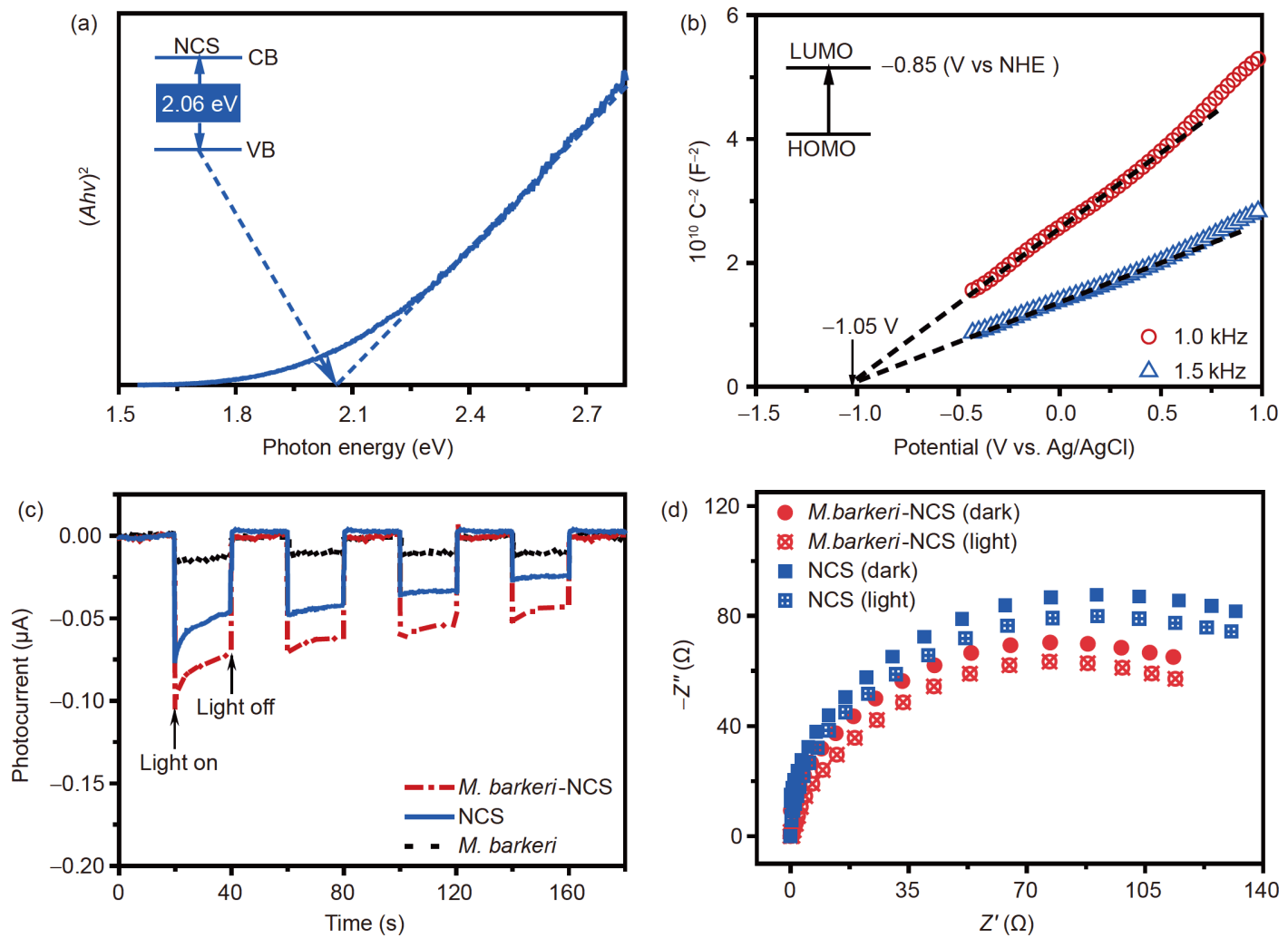

图 3 (网络版彩图) M. barkeri-NCS生物杂化体系的光电化学表征. (a) NCS的禁带宽度图; (b) NCS的莫特-肖特基图; (c) 光照 循环下 M. barkeri-NCS生物杂化体系的I-t图 $(20 \mathrm{~s} / 20 \mathrm{~s}) ;(\mathrm{d}) \mathrm{NCS}$ 和M. barkeri-NCS生物杂化体系的阻抗谱图

Figure 3 (Color online) Photoelectrochemical tests of the M. barkeri-NCS biohybrids. (a) Band gap plot of NCS; (b) Mott-Schottky curves of NCS; (c) I- $t$ curves of the $M$. barkeri-NCS biohybrids with a light on/off cycle $(20 \mathrm{~s} / 20 \mathrm{~s})$; (d) electrical impedance diagrams of NCS and $M$. barkeri-NCS biohybrids.

量几乎忽略不计, 这是因为 $M$. barkeri对光敏感, 光照 可能会阻碍 $M$. barkeri的正常生理代谢以及 $\mathrm{CH}_{4}$ 的生 成 ${ }^{[25]}$. 此外, 虽然碳基半导体催化剂对 $\mathrm{CO}_{2}$ 还原产 $\mathrm{CH}_{4}$ 的积极作用已被广泛报道 ${ }^{[45]}$, 但本研究中单独NCS体 系在光照下几乎不产生 $\mathrm{CH}_{4}$, 这可能是由于NCS中光 生电子与空穴的快速复合限制了光电子转移及 M. barkeri对光生电子的捕获 ${ }^{[46]}$. 需要指出的是, 所制备 NCS 的导带具有将 $\mathrm{CO}_{2}$ 还原为 $\mathrm{CO}$ 的潜力 $\left(\mathrm{CO}_{2}+2 \mathrm{H}^{+}+2 \mathrm{e}^{-} \rightarrow\right.$ $\mathrm{CO}+\mathrm{H}_{2} \mathrm{O}, E_{0}=-0.53 \mathrm{~V}$ vs. NHE, $\mathrm{pH}=7.0$ ), 该过程可能 竞争光电子, 进而限制 $\mathrm{CH}_{4}$ 的生成 ${ }^{[22]}$. 在单独 NCS 体系 中检测到的少量 $\mathrm{CO}(5.46 \pm 0.31 \mu \mathrm{mol} / \mathrm{g})$ 验证了这种可 能. 此外, M. barkeri-NCS生物杂化体系在黑暗条件下 的 $\mathrm{CH}_{4}$ 生成量几乎没有变化, 说明该生物杂化体系产 $\mathrm{CH}_{4}$ 过程需要在光驱动下进行. 为了进一步确认 $\mathrm{CH}_{4}$ 的 来源, 以 ${ }^{13} \mathrm{C}$ 标记的 $\mathrm{NaH}^{13} \mathrm{CO}_{3}$ 作为碳源和电子受体开 展同位素标记实验. 结果仅检测到 ${ }^{13} \mathrm{CH}_{4}(m / z=17)$ 和 ${ }^{13} \mathrm{CO}_{2}(m / z=45)$ 的特征峰(图4(c)), 这说明生物杂化体
系产生的 $\mathrm{CH}_{4}$ 来自于 $\mathrm{CO}_{2}$ 还原. 为了模拟昼-夜循环, 采 用 $12 \mathrm{~h}$ 光与 $12 \mathrm{~h}$ 暗交替循环的方法研究了 M. barkeri$\mathrm{NCS}$ 生物杂化体系的产 $\mathrm{CH}_{4}$ 性能. 如图4(d)所示, 在前 两个光-暗循环期间, M. barkeri-NCS生物杂化体系的 $\mathrm{CH}_{4}$ 产量就达到了 $42.32 \pm 2.07 \mu \mathrm{mol} / \mathrm{g}$, 量子效率最高可 达 $0.08 \%$, 特别是在黑暗阶段 $\mathrm{CH}_{4}$ 产量仍有少量提高. 这 可能是由于在光照条件下产生的 $\mathrm{NADH}$ 等产物可作为 黑暗条件下的额外电子供体, 进而促进 $\mathrm{CH}_{4}$ 的生成 ${ }^{[47]}$.

\subsection{M. barkeri-NCS生物杂化体系产 $\mathrm{CH}_{4}$ 机制}

我们对 $M$. barkeri-NCS生物杂化体系产 $\mathrm{CH}_{4}$ 的机 制进行研究. NADH/NAD比值测试显示, 在光照下, M. barkeri-NCS生物杂化体系具有更高的胞内还原电 位(图5(a)), 这表明光生电子可以在细胞内触发 NADH 的快速生成 ${ }^{[47]}$. 加之积累的 NADH可以作为额外的电 子供体, 这有利于暗循环中 $\mathrm{CH}_{4}$ 的产生. 随着光照时间 的推移, 细胞内NADH浓度显著降低, 这可能是由于牺 

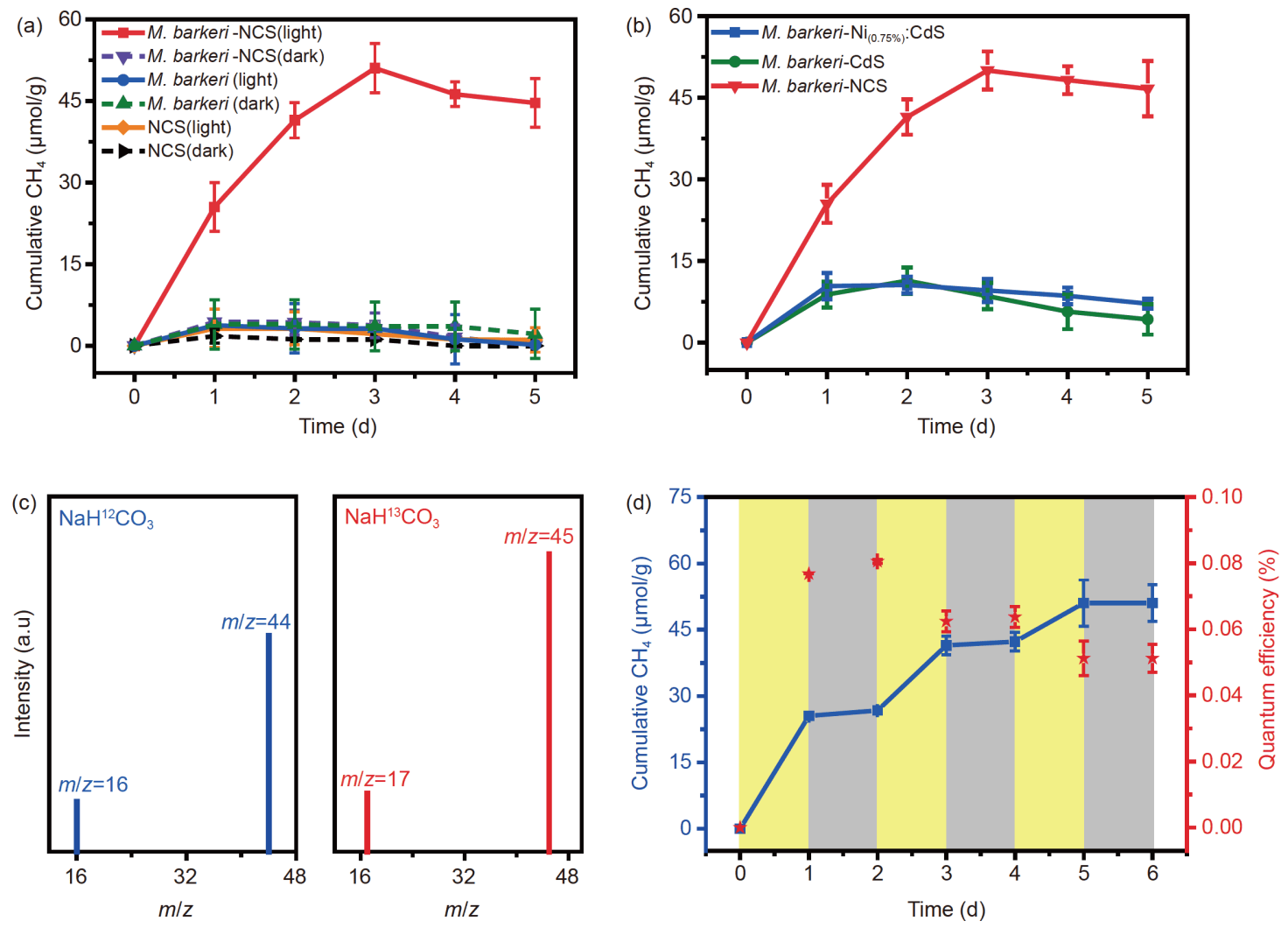

图 4 (网络版彩图) M. barkeri-NCS生物杂化体系产 $\mathrm{CH}_{4}$ 性能. (a) 不同处理组的 $\mathrm{CH}_{4}$ 产量; (b) 不同半导体生物杂化体系的 $\mathrm{CH}_{4}$ 产量; (c) C同位素标记; (d) 光暗循环 $\mathrm{CH}_{4}$ 产量

Figure 4 (Color online) Photocatalytic performance for $\mathrm{CH}_{4}$ production with the M. barkeri-NCS biohybrids. (a) The $\mathrm{CH}_{4}$ yields of different treatments; (b) the $\mathrm{CH}_{4}$ yields with different semiconductor biohybrids; (c) C-labeled plot; (d) the $\mathrm{CH}_{4}$ yields under light-dark cycle conditions.

牲试剂的消耗导致体系中活性氧自由基的浓度不断增 加, 进而影响了M. barkeri的活性. 此外, 膜相关蛋白在 产甲烷菌还原 $\mathrm{CO}_{2}$ 产 $\mathrm{CH}_{4}$ 过程起到了重要的作用 ${ }^{[48]}$. 我 们首先对光照过程中不同处理样品进行总蛋白的提 取, 用其来表征生物量的变化. 结果如图5(b)显示, 在 光照前两天, M. barkeri-NCS生物杂化体系的总蛋白不 断增加, 随后总蛋白量开始下降, 这与 $\mathrm{CH}_{4}$ 积累量变化 相一致. 相比较之下, 其他处理组的总蛋白量从第一天 开始便随着时间推移不断下降, 其中光照下单纯菌 $(M$. barkeri(light))的总蛋白量下降的速率最快，这可能是 由于较高的光照强度导致参与光电子转移的功能蛋白 失活 ${ }^{[49]}$.

为了深入了解膜结合蛋白在 $M$. barkeri-NCS生物 杂化体系光电子转移中的作用，采用 $q R T-P C R$ 对 M. barkeri还原 $\mathrm{CO}_{2}$ 过程中传递电子的主要膜结合蛋 白进行分析，包括铁还原蛋白依赖型氢酶 EchA-F
$\left(\mathrm{H}_{2}+\mathrm{Fd}_{\mathrm{ox}} \rightleftharpoons \mathrm{Fd}_{\mathrm{red}}^{2-}+2 \mathrm{H}^{+}\right)$、甲烷吩嗪依赖型氢酶 VhtACG $\left(\mathrm{H}_{2}+\mathrm{MP} \rightleftharpoons \mathrm{MPH}_{2}\right)$ 和异二硫化物还原酶 $\mathrm{HdrDE}$ $\left(\mathrm{MPH}_{2}+\mathrm{Com}-\mathrm{S}-\mathrm{S}-\mathrm{CoB} \rightleftharpoons \mathrm{MP}+\mathrm{HS}-\mathrm{CoM}+\mathrm{HS}-\mathrm{CoB}\right)$. 图5 (c)表明，光照下EchA-F和VhtACG的相对表达量均有 不同程度的增加，表明氢酶在介导 $M$. barkeri-NCS生 物杂化体系电子传递的过程中有重要作用. 其中 $E \mathrm{chB}$ (2.47 \pm 0.25 倍), $\operatorname{EchE}(1.38 \pm 0.01$ 倍)和 $E \operatorname{ch} F(1.33 \pm 0.06$ 倍 $)$ 的相对表达量显著增加, 这可能是由于大量光生电子 直接或通过 EchB间接催化EchE产生 $\mathrm{H}_{2}$, 进而还原 $\mathrm{EchF}$ 产生的铁氧化蛋白引起. 这一过程产生的铁还原 蛋白可为 $\mathrm{CO}_{2}$ 还原为甲酰甲烷呋喃提供电子供体 ${ }^{[50]}$. 同时, 细胞内产生的 $\mathrm{H}_{2}$ 也可以被 VhtACG, 特别是VhtA 基因捕获和氧化，从而使其相对表达量增加 $1.76 \pm 0.06$ 倍. 以上结果证实, 氢酶可介导碳基半导体产生的光 生电子的传递 ${ }^{[51]}$. 此外, $\mathrm{VhtC}$ 和 HdrE是 M. barkeri重要 的膜结合细胞色素 $\mathrm{b}$ 的组成部分. 光照条件下, $\mathrm{VhtC}$ 

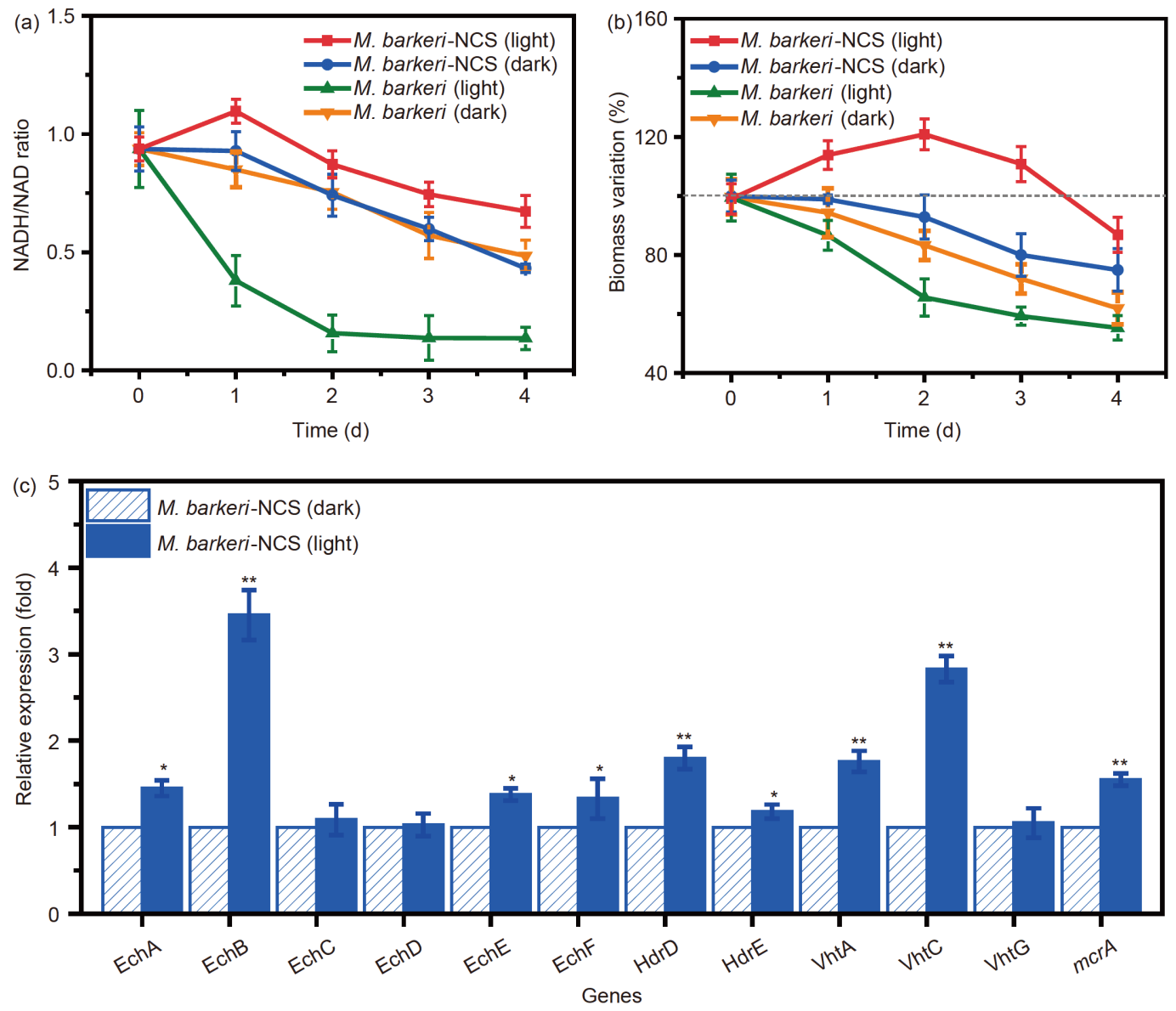

图 5 (网络版彩图) M. barkeri-NCS生物杂化体系产甲烷分子机制. (a) NADH变化; (b) 生物量变化; (c) M. barkeri的Ech, Vht, $\operatorname{Hdr}$ 和 $m c r A$ 表达 $(*$ 表示显著相关, $P<0.05 ; * *$ 表示极显著相关, $P<0.01)$

Figure 5 (Color online) Molecular mechanism of M. barkeri-NCS biohybrids for $\mathrm{CH}_{4}$ production. (a) NADH variation; (b) biomass variation; (c) relative transcript abundance of Ech, Vht, Hdr and $m c r A$ in the M. barkeri-NCS biohybrids (* indicates significant correlation, $P<0.05$; ** indicates extremely significant correlation, $P<0.01)$.

$(2.83 \pm 0.15$ 倍 $)$ 和 $\mathrm{HdrE}(1.18 \pm 0.08$ 倍)的相对表达量均有 增加, 这表明光生电子可能能够直接注入到细胞色素b 中，进而促进 $\mathrm{VhtC}$ 和 $\mathrm{HdrE}$ 进行甲烷吩嗪的氧化还 原 ${ }^{[00,52]}$. 因此，细胞色素介导的机制也是 $M$. barkeri$\mathrm{NCS}$ 生物杂化体系中一个重要的光电子转移途径. 此 外, 作为Hdr的另外一个基因, HdrD相对表达量也增加 $1.82 \pm 0.12$ 倍, 这意味着通过 $H d r E$ 传递的电子或光生电 子可能能够直接催化 $\mathrm{HdrD}$ 生成辅酶 $\mathrm{M}$ 和辅酶 $\mathrm{B}$, 促进 产 $\mathrm{CH}_{4}$ 进程 ${ }^{[53]}$.

甲基辅酶 $\mathrm{M}$ 还原酶( $\mathrm{Mcr}$ ) 是产甲烷菌将甲基最终 转化为 $\mathrm{CH}_{4}$ 的关键功能酶, 而其中 $m c r A$ 基因可以作为 研究产甲烷菌多样性的分子标记物 ${ }^{[54]}$. 为证明传递的 光生电子最终用来生成了 $\mathrm{CH}_{4}$, 对 $m c r A$ 基因进行分析,
结果显示其转录水平显著提高( $1.55 \pm 0.07$ 倍)，表明光 照激发半导体所产生的光生电子能够有效促进氢酶及 细胞色素等关键功能蛋白表达, 进而强化产 $\mathrm{CH}_{4}$ 性能 (图6). 但是, 目前对于 M. barkeri-NCS生物杂化体系能 量转换途径和中间代谢产物等尚不明确，新的电子传 递途径仍有待探索. 此外, M. barkeri的亚基基因表达 不同的原因也值得进一步研究, 解决这些问题有助于 更好地理解和构建生物杂化体系.

\section{4 结果与讨论}

我们利用油菜花粉制备了天然碳基半导体(NCS), 并成功将其应用于 $M$. barkeri-NCS半人工光合系统的 


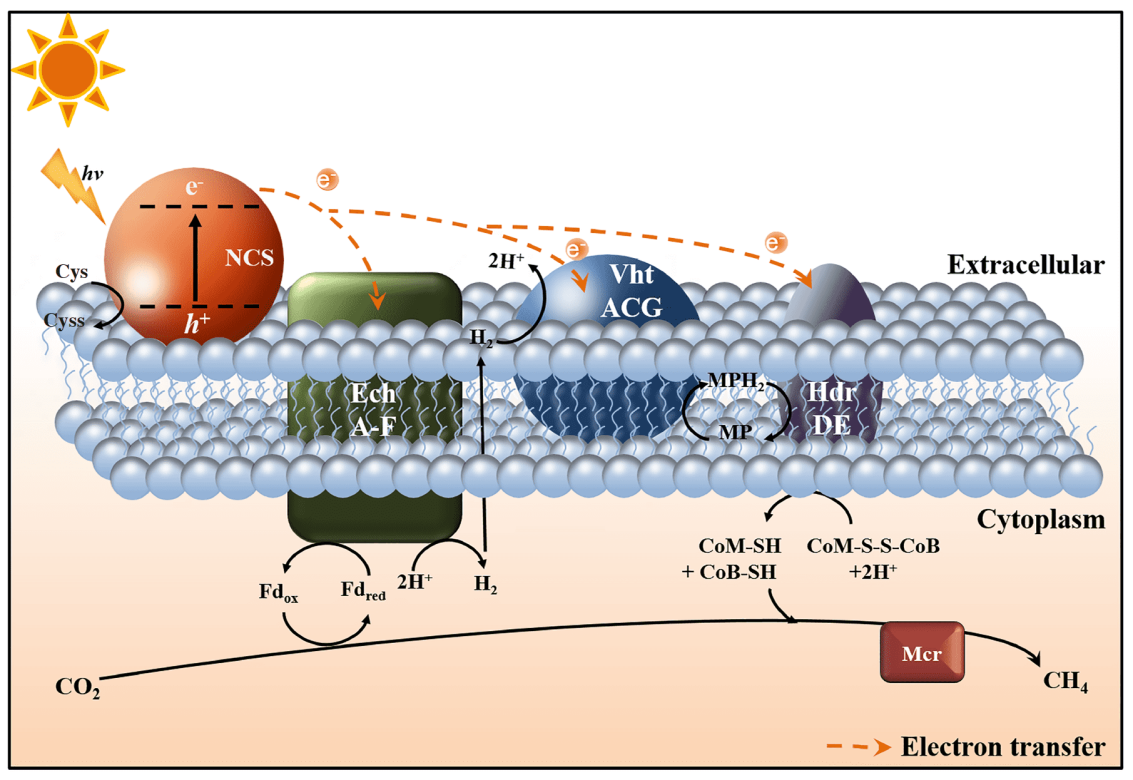

图 6 (网络版彩图) M. barkeri-NCS生物杂化体系电子传递途径

Figure 6 (Color online) Proposed photoelectrons transfer mechanism in the M. barkeri-NCS biohybrids.

构建. 该半人工光合系统在可见光下能够有效驱动 $\mathrm{CO}_{2}$ 还原产 $\mathrm{CH}_{4}$, 最高 $\mathrm{CH}_{4}$ 产量可达 $51 \pm 4.5 \mu \mathrm{mol} / \mathrm{g}$. 机 理分析结果显示, 膜结合蛋白如氢酶和细胞色素在
M. barkeri-NCS半人工光合系统的光电子转移中起着 关键作用. 该研究结果对于构建高效的半人工光合系 统具有重要意义.

\section{参考文献}

1 Olah G A, Goeppert A, Prakash G K S. Chemical recycling of carbon dioxide to methanol and dimethyl ether: From greenhouse gas to renewable, environmentally carbon neutral fuels and synthetic hydrocarbons. J Org Chem, 2009, 74: 487-498

2 Anderson T R, Hawkins E, Jones P D. $\mathrm{CO}_{2}$, the greenhouse effect and global warming: From the pioneering work of Arrhenius and Callendar to today's Earth System Models. Endeavour, 2016, 40: 178-187

3 Janke C, Duyar M S, Hoskins M, et al. Catalytic and adsorption studies for the hydrogenation of $\mathrm{CO}_{2}$ to methane. Appl Catal B-Environ, 2014, 152-153: 184-191

4 Sastre F, Puga A V, Liu L, et al. Complete photocatalytic reduction of $\mathrm{CO}_{2}$ to methane by $\mathrm{H}_{2}$ under solar light irradiation. J Am Chem Soc, 2014, 136: $6798-6801$

5 Kim H R, Razzaq A, Grimes C A, et al. Heterojunction p-n-p $\mathrm{Cu}_{2} \mathrm{O} / \mathrm{S}-\mathrm{TiO}_{2} / \mathrm{CuO}$ : Synthesis and application to photocatalytic conversion of $\mathrm{CO}_{2}$ to methane. $\mathrm{J} \mathrm{CO}_{2}$ Util, 2017, 20: 91-96

6 Wang $\mathrm{H}$, Zhang L, Wang K, et al. Enhanced photocatalytic $\mathrm{CO}_{2}$ reduction to methane over $\mathrm{WO}_{3} \cdot 0.33 \mathrm{H}_{2} \mathrm{O}$ via Mo doping. Appl Catal B-Environ, 2019, 243: 771-779

7 Habisreutinger S N, Schmidt-Mende L, Stolarczyk J K. Photocatalytic reduction of $\mathrm{CO}_{2}$ on $\mathrm{TiO}_{2}$ and other semiconductors. Angew Chem Int Ed, 2013, 52: 7372-7408

8 Lee S H, Choi D S, Kuk S K, et al. Photobiocatalysis: Activating redox enzymes by direct or indirect transfer of photoinduced electrons. Angew Chem Int Ed, 2018, 57: 7958-7985

9 Dobbek H, Svetlitchnyi V, Gremer L, et al. Crystal structure of a carbon monoxide dehydrogenase reveals a [Ni-4Fe-5S] cluster. Science, 2001, 293: $1281-1285$

10 Woolerton T W, Sheard S, Reisner E, et al. Efficient and clean photoreduction of $\mathrm{CO}_{2}$ to $\mathrm{CO}$ by enzyme-modified $\mathrm{TiO}_{2}$ nanoparticles using 
visible light. J Am Chem Soc, 2010, 132: 2132-2133

11 Brown K A, Harris D F, Wilker M B, et al. Light-driven dinitrogen reduction catalyzed by a CdS:nitrogenase MoFe protein biohybrid. Science, 2016, 352: 448-450

12 Ye J, Yu J, Zhang Y, et al. Light-driven carbon dioxide reduction to methane by Methanosarcina barkeri-CdS biohybrid. Appl Catal B-Environ, 2019, 257: 117916

13 Ye J, Ren G, Kang L, et al. Efficient photoelectron capture by Ni decoration in Methanosarcina barkeri-CdS biohybrids for enhanced photocatalytic $\mathrm{CO}_{2}$-to- $\mathrm{CH}_{4}$ conversion. iScience, 2020, 23: 101287

14 Chen M F, Huang C Z, Pu D Y, et al. Toxic effects of CdSe/ZnS QDs to zebrafish embryos (in Chinese). Environ Sci, 2015, 36: 719-726 [陈幕飞, 黄承志, 蒲德永, 等. CdSe/ZnS量子点对斑马鱼胚胎发育的毒性效应. 环境科学, 2015, 36: 719-726]

15 Svitkova V, Blaskovicova J, Tekelova M, et al. Assessment of CdS quantum dots effect on UV damage to DNA using a DNA/quantum dots structured electrochemical biosensor and DNA biosensing in solution. Sens Actuat B-Chem, 2017, 243: 435-444

16 Low J, Cheng B, Yu J, et al. Carbon-based two-dimensional layered materials for photocatalytic $\mathrm{CO}_{2}$ reduction to solar fuels. Energy Storage Mater, 2016, 3: 24-35

17 Masih D, Ma Y, Rohani S. Graphitic $\mathrm{C}_{3} \mathrm{~N}_{4}$ based noble-metal-free photocatalyst systems: A review. Appl Catal B-Environ, 2017, 206: 556-588

18 Wang B, Jiang Z, Yu J C. Treated rape pollen: A metal-free visible-light-driven photocatalyst from nature for efficient water disinfection. J Mater Chem A, 2019, 7: 9335-9344

19 Choi Y, Zheng X T, Tan Y N. Bioinspired carbon dots (biodots): Emerging fluorophores with tailored multiple functionalities for biomedical, agricultural and environmental applications. Mol Syst Des Eng, 2020, 5: 67-90

20 Sun J, Zhang J, Zhang M, et al. Bioinspired hollow semiconductor nanospheres as photosynthetic nanoparticles. Nat Commun, 2012, 3: 1139

21 Xiao K M, Wang T Q, Sun M Z, et al. Photocatalytic bacterial inactivation by a rape pollen-MoS $\mathrm{M}_{2}$ biohybrid catalyst: Synergetic effects and inactivation mechanisms. Environ Sci Technol, 2020, 54: 537-549

22 Jiang Z, Sun H, Wang T, et al. Nature-based catalyst for visible-light-driven photocatalytic $\mathrm{CO}_{2}$ reduction. Energ Environ Sci, 2018, 11: 23822389

23 Lou X W D, Archer L A, Yang Z. Hollow micro-/nanostructures: Synthesis and applications. Adv Mater, 2008, 20: 3987-4019

24 Pellegrin Y, Odobel F. Sacrificial electron donor reagents for solar fuel production. Comptes Rendus Chimie, 2017, 20: 283-295

25 Sakimoto K K, Wong A B, Yang P. Self-photosensitization of nonphotosynthetic bacteria for solar-to-chemical production. Science, 2016, 351: 74-77

26 Wang B, Xiao K, Jiang Z, et al. Biohybrid photoheterotrophic metabolism for significant enhancement of biological nitrogen fixation in pure microbial cultures. Energ Environ Sci, 2019, 12: 2185-2191

27 Ito N, Sato Y, Song P K, et al. Electrical and optical properties of amorphous indium zinc oxide films. Thin Solid Films, 2006, 496: 99-103

28 Özgenç Ö, Durmaz S, Boyaci I H, et al. Determination of chemical changes in heat-treated wood using ATR-FTIR and FT Raman spectrometry. SpectroChim Acta Part A-Mol Biomol Spectr, 2017, 171: 395-400

29 Di T, Cheng B, Ho W, et al. Hierarchically CdS- $\mathrm{Ag}_{2} \mathrm{~S}$ nanocomposites for efficient photocatalytic $\mathrm{H}_{2}$ production. Appl Surf Sci, 2019, 470: 196204

30 Yang Q, Yang C C, Lin C H, et al. Metal-organic-framework-derived hollow N-doped porous carbon with ultrahigh concentrations of single Zn atoms for efficient carbon dioxide conversion. Angew Chem, 2019, 131: 3549-3553

31 Peng J, Chen N, He R, et al. Electrochemically driven transformation of amorphous carbons to crystalline graphite nanoflakes: A facile and mild graphitization method. Angew Chem, 2017, 129: 1777-1781

32 Lee W H, Lee J G, Reucroft P J. XPS study of carbon fiber surfaces treated by thermal oxidation in a gas mixture of $\mathrm{O}_{2} /\left(\mathrm{O}_{2}+\mathrm{N}_{2}\right)$. Appl Surf Sci, 2001, 171: 136-142

33 Fan L Z, Qiao S, Song W, et al. Effects of the functional groups on the electrochemical properties of ordered porous carbon for supercapacitors. Electrochim Acta, 2013, 105: 299-304

34 Yuan G, Zhao X, Liang Y, et al. Small nitrogen-doped carbon dots as efficient nanoenhancer for boosting the electrochemical performance of three-dimensional graphene. J Colloid Interface Sci, 2019, 536: 628-637

35 Rodriguez J A, Jirsak T, Chaturvedi $\mathrm{S}$, et al. Reaction of $\mathrm{SO}_{2}$ with $\mathrm{ZnO}(0001)-\mathrm{O}$ and $\mathrm{ZnO}$ powders: Photoemission and XANES studies on the formation of $\mathrm{SO}_{3}$ and $\mathrm{SO}_{4}$. Surf Sci, 1999, 442: 400-412 
36 Liao S, Donggen H, Yu D, et al. Preparation and characterization of $\mathrm{ZnO} / \mathrm{TiO}_{2}, \mathrm{SO}_{4}{ }^{2-} / \mathrm{ZnO} / \mathrm{TiO}_{2}$ photocatalyst and their photocatalysis. J PhotoChem PhotoBiol A-Chem, 2004, 168: 7-13

37 Rong J, Qiu F, Zhang T, et al. A facile strategy toward 3D hydrophobic composite resin network decorated with biological ellipsoidal structure rapeseed flower carbon for enhanced oils and organic solvents selective absorption. Chem Eng J, 2017, 322: 397-407

38 Ming J, Wu Y, Yu Y, et al. Steaming multiwalled carbon nanotubes via acid vapour for controllable nanoengineering and the fabrication of carbon nanoflutes. Chem Commun, 2011, 47: 5223-5225

39 Guan X, Chen G, Shang C. ATR-FTIR and XPS study on the structure of complexes formed upon the adsorption of simple organic acids on aluminum hydroxide. J Environ Sci, 2007, 19: 438-443

40 Huang Y, Wang Y, Bi Y, et al. Preparation of 2D hydroxyl-rich carbon nitride nanosheets for photocatalytic reduction of $\mathrm{CO}_{2}$. RSC Adv, 2015, 5: 33254-33261

41 Vogel R, Hoyer P, Weller H. Quantum-Sized PbS, CdS, $\mathrm{Ag}_{2} \mathrm{~S}, \mathrm{Sb}_{2} \mathrm{~S}_{3}$, and $\mathrm{Bi}_{2} \mathrm{~S}_{3}$ particles as sensitizers for various nanoporous wide-bandgap semiconductors. J Phys Chem, 2002, 98: 3183-3188

42 Gelderman K, Lee L, Donne S W. Flat-band potential of a semiconductor: using the Mott-Schottky equation. J Chem Educ, 2007, 84: 685

43 Cestellos-Blanco S, Zhang H, Kim J M, et al. Photosynthetic semiconductor biohybrids for solar-driven biocatalysis. Nat Catal, 2020, 3: 245-255

44 Stams A J M, Plugge C M. Electron transfer in syntrophic communities of anaerobic bacteria and archaea. Nat Rev Microbiol, 2009, 7: 568-577

45 Jo W K, Kumar S, Tonda S. N-doped C dot/CoAl-layered double hydroxide/g- $\mathrm{C}_{3} \mathrm{~N}_{4}$ hybrid composites for efficient and selective solar-driven conversion of $\mathrm{CO}_{2}$ into $\mathrm{CH}_{4}$. Compos Part B-Eng, 2019, 176: 107212

$46 \mathrm{Xu} \mathrm{H} \mathrm{Q}, \mathrm{Hu}$ J, Wang D, et al. Visible-light photoreduction of $\mathrm{CO}_{2}$ in a metal-organic framework: boosting electron-hole separation via electron trap states. J Am Chem Soc, 2015, 137: 13440-13443

47 Zhang R, He Y, Yi J, et al. Proteomic and metabolic elucidation of solar-powered biomanufacturing by bio-abiotic hybrid system. Chem, 2020, 6: 234-249

48 Cheng L, Zheng Z Z, Wang C, et al. Recent advances in methanogens. Microbiol China, 2016, 43: 1143-1164 [承否, 郑珍珍, 王聪, 等. 产甲烷 古菌研究进展. 微生物学通报, 2016, 43: 1143-1164]

49 Brown K A, Wilker M B, Boehm M, et al. Characterization of photochemical processes for $\mathrm{H}_{2}$ production by CdS nanorod-[FeFe] hydrogenase complexes. J Am Chem Soc, 2012, 134: 5627-5636

50 Lovley D R. The hydrogen economy of Methanosarcina barkeri: Life in the fast lane. J Bacteriol, 2018, 200: JB.00445-18

51 Hola K, Pavliuk M V, Németh B, et al. Carbon dots and [FeFe]-hydrogenase biohybrid assemblies for efficient light-driven hydrogen evolution. ACS Catal, 2020, 10: 9943-9952

52 Kornienko N, Sakimoto K K, Herlihy D M, et al. Spectroscopic elucidation of energy transfer in hybrid inorganic-biological organisms for solarto-chemical production. Proc Natl Acad Sci USA, 2016, 113: 11750-11755

53 Kulkarni G, Mand T D, Metcalf W W. Energy conservation via hydrogen cycling in the methanogenic archaeon Methanosarcina barkeri. MBio, 2018, 9: e01256-18

54 Lueders T, Chin K J, Conrad R, et al. Molecular analyses of methyl-coenzyme M reductase alpha-subunit ( $m c r A$ ) genes in rice field soil and enrichment cultures reveal the methanogenic phenotype of a novel archaeal lineage. Environ Microbiol, 2001, 3: 194-204 


\title{
Visible light-driven Methanosarcina barkeri-natural carbon-based semiconductor for methane production
}

\author{
ZHANG YiYun ${ }^{1}$, REN GuoPing ${ }^{1}$, HU AnDong ${ }^{1}$, JIN ShuGuang ${ }^{2}$, YE Jie ${ }^{1} \&$ ZHOU ShunGui ${ }^{1}$ \\ ${ }^{1}$ College of Resources and Environment, Fujian Agriculture and Forestry University, Fuzhou 350002, China; \\ ${ }^{2}$ Research Center for Eco-Environmental Sciences, Chinese Academy of Sciences, Beijing 100085, China
}

The reduction of carbon dioxide to methane with high calorific values by a semi-artificial photosynthetic system (nonphotosynthetic microorganism-semiconductor biohybrids) contributes to the alleviation of the global greenhouse effect and energy crisis. As a key component, the structure and properties of semiconductor nanoparticles significantly affect the biohybrid performance. In this study, rape pollen is used as the raw material to successfully construct Methanosarcina barkeri-natural carbon-based semiconductor biohybrids (M. barkeri-NCS) for carbon dioxide reduction to methane. The results indicate that the prepared natural carbon-based semiconductors have distinct advantages, such as a good visible light response and a large pore volume. Meanwhile, the M. barkeriNCS biohybrids have excellent photoelectrical properties, and the methane yield of which reaches up to $51 \pm 4.5 \mu \mathrm{mol} / \mathrm{g}$ under visible light irradiation $\left(1.0 \pm 0.2 \mathrm{~mW} / \mathrm{cm}^{2}\right)$. The performed real-time quantitative polymerase chain reaction (qPCR) analysis further reveals that the genes related to the membrane-bond hydrogenase and cytochrome of M. barkeri, especially EchB (2.47 \pm 0.25 times) and VhtC ( $2.83 \pm 0.15$ times), are significantly up-regulated, indicating their key roles in photoelectron transfer, trap, and utilization. The results are expected to provide theoretical support for constructing an efficient semi-artificial photosynthetic system.

photocatalysis, methanogenesis, biohybrid, Methanosarcina barkeri, natural carbon-based semiconductors

doi: $10.1360 /$ SST-2020-0414 